\title{
Effect of Coexisting Materials on Secondary Ettringite Formation
}

\author{
Kennosuke Sato ${ }^{1}$, Tsuyoshi Saito ${ }^{2}$ and Tatsuhiko Saeki ${ }^{2}$ \\ ${ }^{1}$ Department of Civil \& Environmental Engineering, University of Yamanashi, 4-3-11, Takeda, Kofu, \\ Yamanashi, 400-8511, Japan, satok@ yamanashi.ac.jp \\ ${ }^{2}$ Department of Civil Engineering, Niigata University, 8050, Ikarashi Ninocho, Nishiku, Niigata, 950- \\ 2181, Japan, tsaito@eng.niigata-u.ac.jp
}

\begin{abstract}
The expansion of cement paste can occur as a result of secondary ettringite formation due to attack by sulfates. It has been proposed that this expansion is affected by coexisting hydration products such as calcium-silicate-hydrates $(C-S-H)$, although the mechanism has not yet been clarified. The present study experimentally examined the effects of coexisting materials on secondary ettringite formation. Synthesized monosulfate and coexisting materials such as $C$-S-H were mixed with a sodium sulfate solution. The secondary ettringite proportion was markedly increased by the presence of $C-S-H$, and calcium-aluminate-silicate-hydrates $(C-A-S-H)$ containing four-coordinate $A l$ were formed in these samples. It is evident that ettringite is likely to form from four-coordinate Al, and that $C-S-H$ promotes secondary ettringite formation because it transitions six-coordinate Al derived from the monosulfate to four-coordinate Al by substituting Al in the Si chains.
\end{abstract}

Keywords: Sulfate Attack, DEF, Secondary Ettringite Formation, Coexisting Materials, $C$-S-H.

\section{Introduction}

Expansion due to sulfates is typically referred to as either external or internal sulfate attack, depending on the sulfate source. Internal sulfate attack after high temperature curing is also referred to as delayed ettringite formation (DEF) (Collepardi, 2003). Both external and internal sulfate attack are attributed to secondary ettringite formation in the cement paste.

Ettringite has the composition $\mathrm{C}_{6} \mathrm{~A}_{3} \mathrm{H}_{32}$ and is formed from tricalcium aluminate $\left(\mathrm{C}_{3} \mathrm{~A}\right)$ in Portland cement or from aluminum in supplementary cementitious materials during the early stages of hydration. Ettringite is subsequently converted to a monosulfate (Ms) form having the formula $\mathrm{C}_{4} \mathrm{~A} \overline{\mathrm{S}} \mathrm{H}_{12}$ as the sulfate ion concentration in the liquid phase decreases. When sulfate ions are supplied to the hardened cement paste they react with the Ms to reform socalled secondary ettringite. However, the mechanisms which can explain all expansions due to secondary ettringite formation in a unified manner has not yet been proposed.

It has been suggested that the expansion due to secondary ettringite formation is affected by the properties of hydration products coexisting with the ettringite, such as calcium-silicatehydrates (C-S-H). Taylor et al. (2001) proposed the DEF expansion mechanism in a mortar. According to this mechanism, ettringite may have a greater degree of expandability when it is formed in the outer C-S-H near the boundary between two C-S-H phases (outer C-S-H and inner C-S-H) than when it is formed in the outer C-S-H far from the boundary.

The goal of the present study was to experimentally examine the effects of coexisting materials on secondary ettringite formation. This was accomplished using a synthesized Ms sample in conjunction with coexisting materials such as C-S-H. The Ms and other materials were mixed and hydrated using a sodium sulfate solution, followed by analysis. 


\section{Methods and Materials}

\subsection{Preparation of Materials}

The Ms was prepared from a suspension of a 1:1 molar mixture of $\mathrm{C}_{3} \mathrm{~A}$, which was prepared by calcining of $\mathrm{CaCO}_{3}$ and $\mathrm{Al}_{2} \mathrm{O}_{3}$, and $\mathrm{CaSO}_{4}$ in deionized water, at a water to solid mass ratio of 10:1. The solid and aqueous phases were separated after curing at $20^{\circ} \mathrm{C}$ for $14 \mathrm{~d}$.

$\mathrm{C}-\mathrm{S}-\mathrm{H}$, calcium hydroxide $(\mathrm{CH})$ and hydrogarnet $(\mathrm{HG})$ were used as the coexisting materials in this work. Because silica stone does not react at ambient temperature and pressure, silica stone powder (SSP) was also used for the purposes of comparison with other coexisting materials. In addition, amorphous silica (AS) and Al-substituted C-S-H (C-A-S-H) were used in verification experiments. Three $\mathrm{C}-\mathrm{S}-\mathrm{H}$ samples having different $\mathrm{CaO}$ to $\mathrm{SiO}_{2}$ molar ratios (C/S ratio) (of $0.80,1.00$ and 1.50) were synthesized by reacting mixtures of $\mathrm{CH}$, ethyl silicate and deionized water for $2 \mathrm{~d}$ at $40{ }^{\circ} \mathrm{C}$, after which the solid and aqueous phases were separated by vacuum filtration. $\mathrm{HG}$ was synthesized via the reaction of $\mathrm{C}_{3} \mathrm{~A}$ with deionized water at a water to solid mass ratio of $1: 1$. Samples were cured for $28 \mathrm{~d}$ at $40{ }^{\circ} \mathrm{C}$, after which the solid phase was separated by vacuum filtration. C-A-S-H was synthesized based on the method of Pardal et al. (2009). The CH, AS and SSP (purity > 96\%) used in this work were all commercially-available products.

These materials were dried under $110{ }^{\circ} \mathrm{C}$ in a drying oven (defined as $0 \% \mathrm{RH}$ ), and subsequently crushed into particles smaller than $90 \mu \mathrm{m}$. The $\mathrm{H}_{2} \mathrm{O}$ to $\mathrm{SiO}_{2}$ molar ratios of C-S-

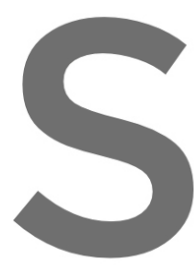
$\mathrm{H}$ having the $\mathrm{C} / \mathrm{S}$ ratios

2.2 Mixing with a Sodium Sulfate Solution The mixing proportions of the Ms and the cox
Herein, the C-S-H and C-A-S-H specimens are
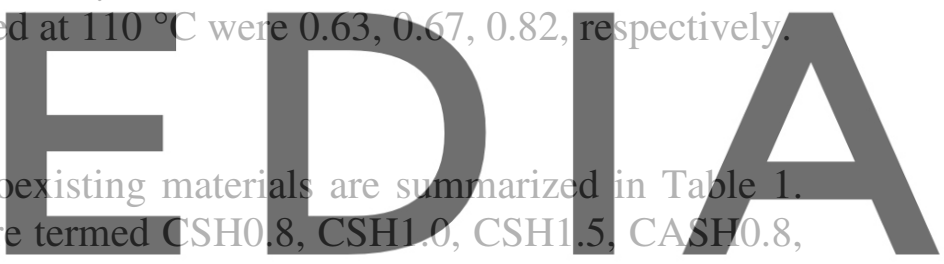
CASH1.0 and CASH1.4, where the numerical portion of the name gives the C/S ratio. The

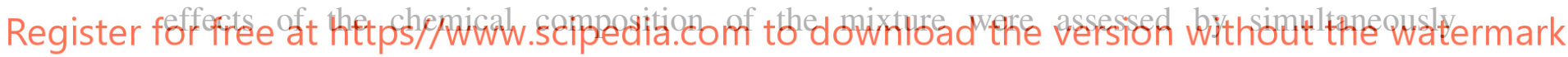

Table 1. Specimen proportions.

\begin{tabular}{|c|c|c|c|c|c|c|c|c|c|c|c|}
\hline \multirow[b]{2}{*}{ Sample name } & \multicolumn{11}{|c|}{ Powder composition (mass\%) } \\
\hline & Ms & $\begin{array}{c}\text { CSH } \\
0.8\end{array}$ & $\begin{array}{c}\text { CSH } \\
1.0\end{array}$ & $\begin{array}{c}\text { CSH } \\
1.5\end{array}$ & $\mathrm{CH}$ & HG & SSP & AS & $\begin{array}{c}\text { CASH } \\
0.8\end{array}$ & $\begin{array}{c}\text { CASH } \\
1.0\end{array}$ & $\begin{array}{c}\text { CASH } \\
1.4\end{array}$ \\
\hline $\mathrm{Ms}+\mathrm{CSH} 0.8$ & 50 & 50 & - & - & - & - & - & - & - & - & - \\
\hline Ms+CSH 1.0 & 50 & - & 50 & - & - & - & - & - & - & - & - \\
\hline $\mathrm{Ms}+\mathrm{CSH} 1.5$ & 50 & - & - & 50 & - & - & - & - & - & - & - \\
\hline $\mathrm{Ms}+\mathrm{CH}$ & 50 & - & - & - & 50 & - & - & - & - & - & - \\
\hline $\mathrm{Ms}+\mathrm{HG}$ & 50 & - & - & - & - & 50 & - & - & - & - & - \\
\hline $\mathrm{Ms}+\mathrm{SSP}$ & 50 & - & - & - & - & - & 50 & - & - & - & - \\
\hline $\mathrm{Ms}+\mathrm{AS}$ & 50 & - & - & - & - & - & - & 50 & - & - & - \\
\hline $\mathrm{Ms}+(\mathrm{CH}+\mathrm{AS}) 1.0$ & 50 & - & - & - & 27.61 & - & - & 22.39 & - & - & - \\
\hline $\mathrm{Ms}+(\mathrm{CH}+\mathrm{AS}) 1.5$ & 50 & - & - & - & 32.46 & - & - & 17.54 & - & - & - \\
\hline Ms+CASH 0.8 & 50 & - & - & - & - & - & - & - & 50 & - & - \\
\hline Ms+CASH 1.0 & 50 & - & - & - & - & - & - & - & - & 50 & - \\
\hline Ms+CASH 1.4 & 50 & - & - & - & - & - & - & - & - & - & 50 \\
\hline
\end{tabular}


combining $\mathrm{CH}$ and $\mathrm{AS}$ with the Ms. In these trials, the $\mathrm{CH}$ and $\mathrm{AS}$ were mixed so that the $\mathrm{C} / \mathrm{S}$ ratio was either 1.00 or 1.50 and the mixture was combined with the Ms at a mass ratio of 1:1.

Each mixture of the Ms and the coexisting materials were mixed with a $0.5 \mathrm{M}$ sodium sulfate solution at a liquid to powder mass ratio of 2:1. They were manually mixed for $3 \mathrm{~m}$ and transferred into a plastic bottle and cured at $20^{\circ} \mathrm{C}$ for $1 \mathrm{~d}$.

After the curing, the samples were broken into small pieces and immersed in acetone for 2 $\mathrm{d}$ to prevent further hydration. These specimens were subsequently placed under vacuum to remove the acetone and stored in a vacuum desiccator in the presence of silica gel for $2 \mathrm{~d}$. The samples were crushed into particles smaller than $90 \mu \mathrm{m}$ and dried at $20{ }^{\circ} \mathrm{C}$ and $11 \% \mathrm{RH}$ using a saturated $\mathrm{LiCl}$ solution in a vacuum desiccator until the sample mass no longer changed.

\subsection{Analysis}

Powder XRD was used for the identification and quantification of hydration products after mixing with the sodium sulfate solution.

For the measurement of the $\mathrm{pH}$ and ionic composition of the liquid phase, a Ms specimen together with coexisting materials were mixed with a $0.5 \mathrm{M}$ sodium sulfate solution at a liquid to powder mass ratio of 3:1. After mixing, each sample was placed in a plastic bottle and then cured at $20^{\circ} \mathrm{C}$ for $1 \mathrm{~d}$, after which the solid and liquid phases were separated by centrifugation. The $\mathrm{pH}$ of the liquid phase was measured using a glass electrode $\mathrm{pH}$ meter and the concentrations of $\mathrm{Na}^{+}, \mathrm{Ca}^{2+}$ and $\mathrm{SO}_{4}^{2-}$ ions in the liquid phase were analyzed.

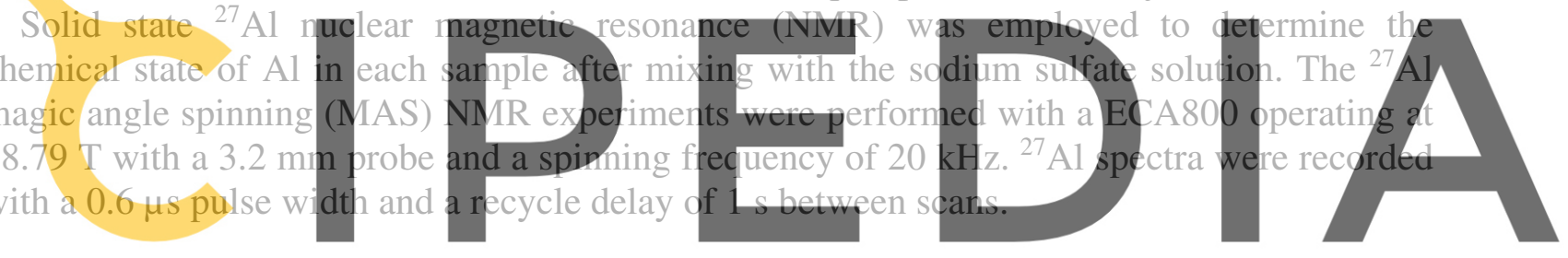

3 Results

Register for free at https//www.scipedia.com to download the version without the watermark 3.1 Formation Characteristics of Secondary Ettringite

Figure 1 shows the XRD patterns of Ms samples with each coexisting material after mixing with the sodium sulfate solution. SSP does not react at ambient temperature and pressure, and so does not contribute to secondary ettringite formation. The ettringite peaks of the $\mathrm{Ms}+\mathrm{CH}$ and Ms+HG were not increased in intensity as compared with Ms+SSP. Thus, when $\mathrm{CH}$ and $\mathrm{HG}$ coexist (that is, even when the $\mathrm{Ca}$ and $\mathrm{Al}$ necessary for the formation of the secondary ettringite are supplied), there was almost no secondary ettringite formation. In contrast, the diffraction peaks due to Ms almost disappeared while those resulting from ettringite increased when C-S-H was added to the Ms.

\subsection{Effects of pH and Calcium Leaching}

The $\mathrm{pH}$ values and ionic compositions of the liquid phases after mixing with the sodium sulfate solution are provided in Table 2. In all cases, the $\mathrm{pH}$ was in the range of 11.57 to 13.39, which is associated with the stable formation of ettringite (Stark and Wicht, 2003; Shimada et al., 2005). The Ms+CSH1.5 had the highest $\mathrm{Ca}^{2+}$ concentration, and the values for the $\mathrm{Ms}+\mathrm{CSH} 0.8$ and Ms+CH were especially close. The $\mathrm{pH}$ of the Ms+CH was higher than that 


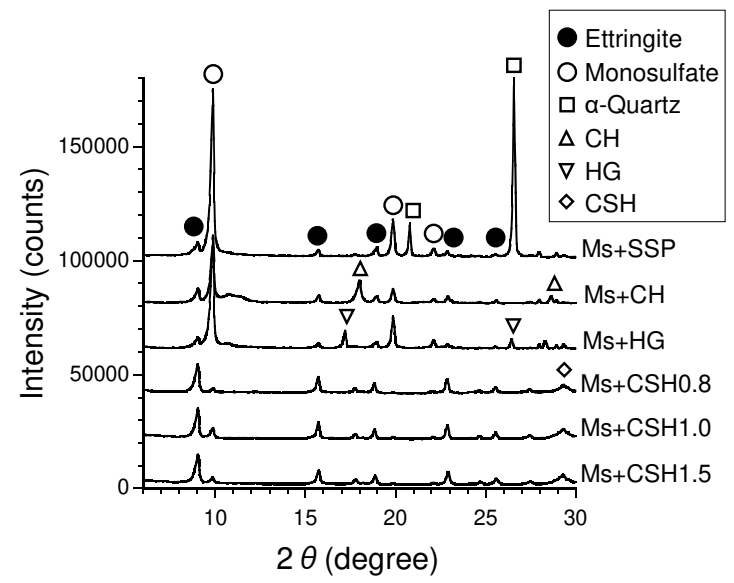

Figure 1. XRD patterns of monosulfate specimens with coexisting materials after mixing with a sodium sulfate solution.

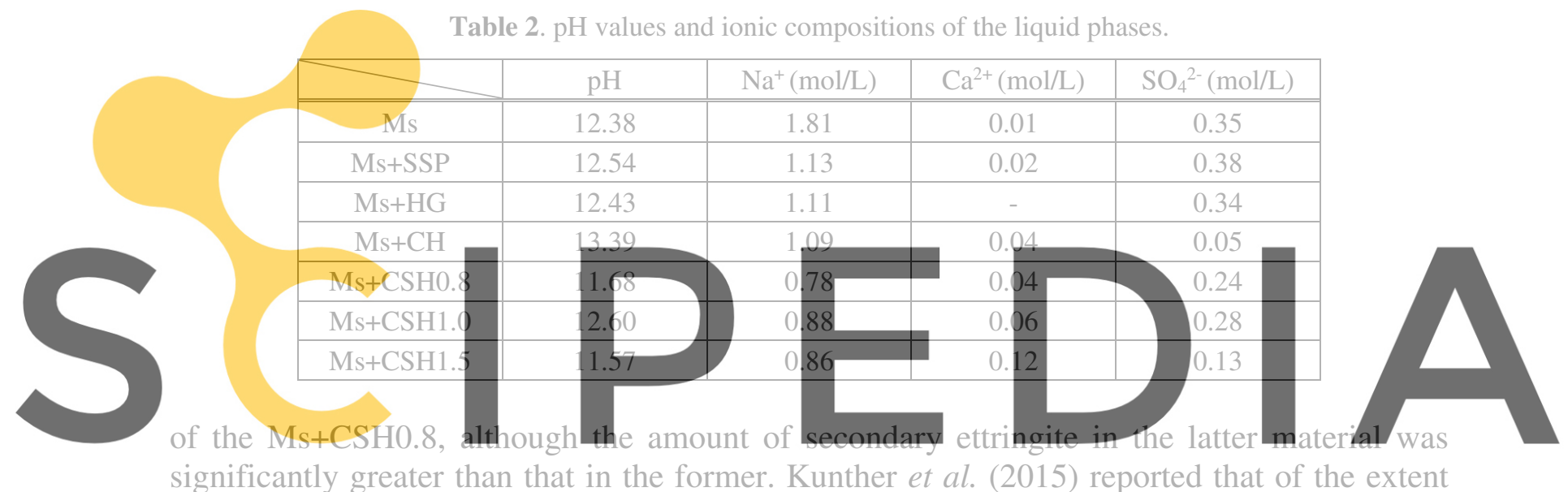

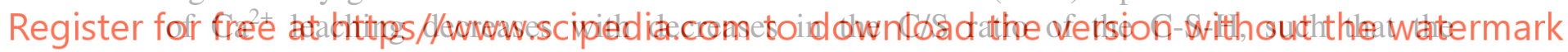
supersaturation of ettringite in the pore solution decreases and expansion of the mortar is suppressed. This suggests that a higher $\mathrm{Ca}^{2+}$ concentration in the liquid phase will promote secondary ettringite formation. However, the results of this study show large differences in the extent of secondary ettringite formation, even when the $\mathrm{Ca}^{2+}$ concentration in the liquid phase is constant. Moreover, although the $\mathrm{Ca}^{2+}$ concentration of the liquid phase was slightly higher in the case of the Ms+CSH1.0 compared with the Ms+CSH0.8, and both $\mathrm{pH}$ values were in the range required for ettringite to be stable, the amount of secondary ettringite in the latter material was greater. Thus, the promotion of secondary ettringite formation due to the presence of $\mathrm{C}-\mathrm{S}-\mathrm{H}$ is not completely explained by conventional theories regarding the effects of the $\mathrm{pH}$ and $\mathrm{Ca}^{2+}$ concentration of the liquid phase.

\subsection{Effects of Ca and Si-Based Materials}

$\mathrm{Si}$ in the C-S-H is thought to have played an important role in secondary ettringite formation in the present work. Figure 2 shows the XRD patterns of Ms specimens with added Ca and Sibased materials after mixing with the sodium sulfate solution. For comparison, the XRD patterns generated by the Ms+SSP, Ms+CH, Ms+CSH1.0 and Ms+CSH1.5 are also provided 


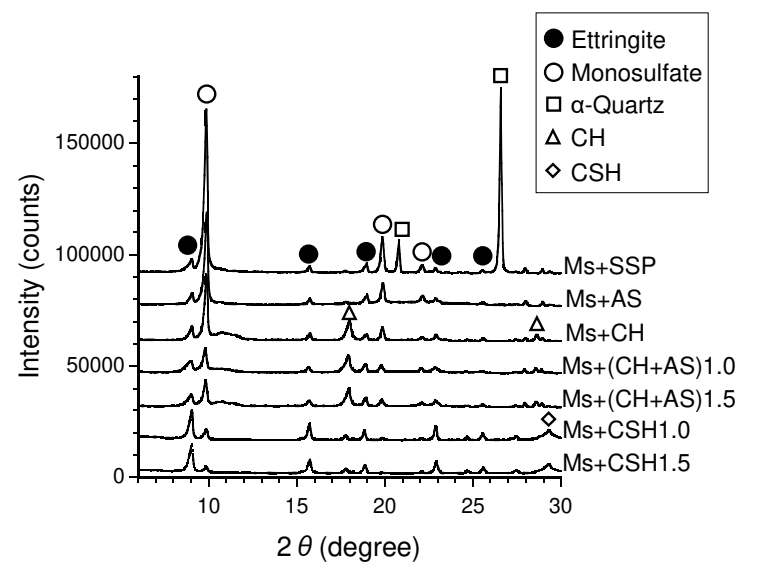

Figure 2. XRD patterns of monosulfate specimens with added $\mathrm{Ca}$ and $\mathrm{Si}$ after mixing with a sodium sulfate solution.

in the figure. These patterns demonstrate that the Ms diffraction peaks produced by the Ms+AS were slightly less intense than those in the Ms+SSP pattern. When both $\mathrm{CH}$ and AS were present, the Ms peaks were further decreased. Therefore, it appears that the simultaneous addition of both $\mathrm{Ca}$ and $\mathrm{Si}$ promoted the dissolution of the Ms. Conversely, the ettringite peaks did not increase significantly even when both $\mathrm{CH}$ and $\mathrm{AS}$ coexisted. Thus, even when the chemical composition in the sample is the same as that of $\mathrm{C}-\mathrm{S}-\mathrm{H}$, the amount of secondary

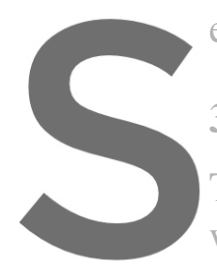
ettringite is greatly increased only when $\mathrm{C}-\mathrm{S}-\mathrm{H}$ is present. 3.4 Evaluation of the Chemical State of Al The chemical state of Al, which is an importan was investigated using ${ }^{27}$ Al NMR. Figure 3
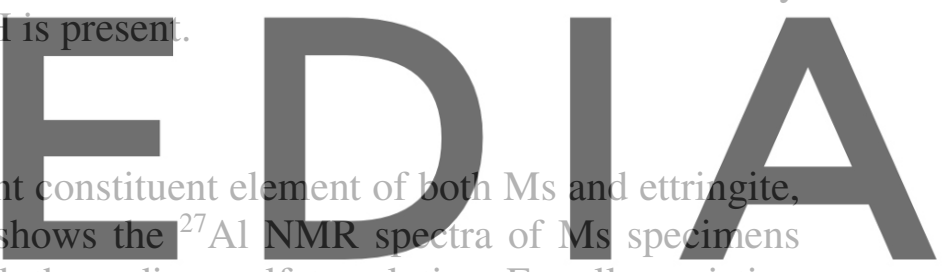

with each coexisting material after mixing with the sodium sulfate solution. For all coexisting

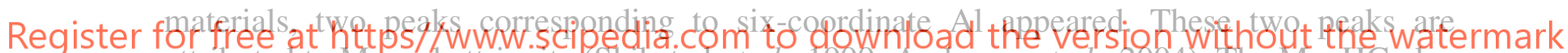
attributed to Ms and ettringite (Skibsted et al., 1999; Andersen et al., 2004). The Ms+HG also generated a HG peak close to the ettringite peak (Cuesta et al., 2017). In the case of the sample without $\mathrm{C}-\mathrm{S}-\mathrm{H}$, a six-coordinate $\mathrm{Al}$ peak produced by the Ms is clearly present. In contrast, the spectra obtained from the samples with C-S-H contain a significantly reduced Ms peak along with a much more intense ettringite peak. Thus, these ${ }^{27} \mathrm{Al} \mathrm{NMR}$ data also demonstrate that the coexistence of C-S-H promoted secondary ettringite formation.

Moreover, each of the three samples containing C-S-H generated a broad peak corresponding to four-coordinate Al. This peak is also generated by C-A-S-H, in which $\mathrm{Al}$ is substituted for $\mathrm{Si}$ in the silicate chains of $\mathrm{C}-\mathrm{S}-\mathrm{H}$ at pairing and bridging sites (Richardson, 2004). Because the bridging sites in the silicate chains are increased as the C/S ratio decreases, $\mathrm{Al}$ is more readily substituted for $\mathrm{Si}$ at these sites (Pardal et al., 2012; Renaudin et al., 2009). It is therefore apparent that, in samples containing C-S-H, the $\mathrm{Si}$ in the silicate chains were substituted with $\mathrm{Al}$ released by dissolution of the Ms to generate C-A-S-H.

\subsection{Effect of the Presence of C-A-S-H}

Figure 4 presents the XRD patterns of Ms specimens with added C-A-S-H after mixing with the sodium sulfate solution, along with the patterns of the C-S-H samples for comparison 

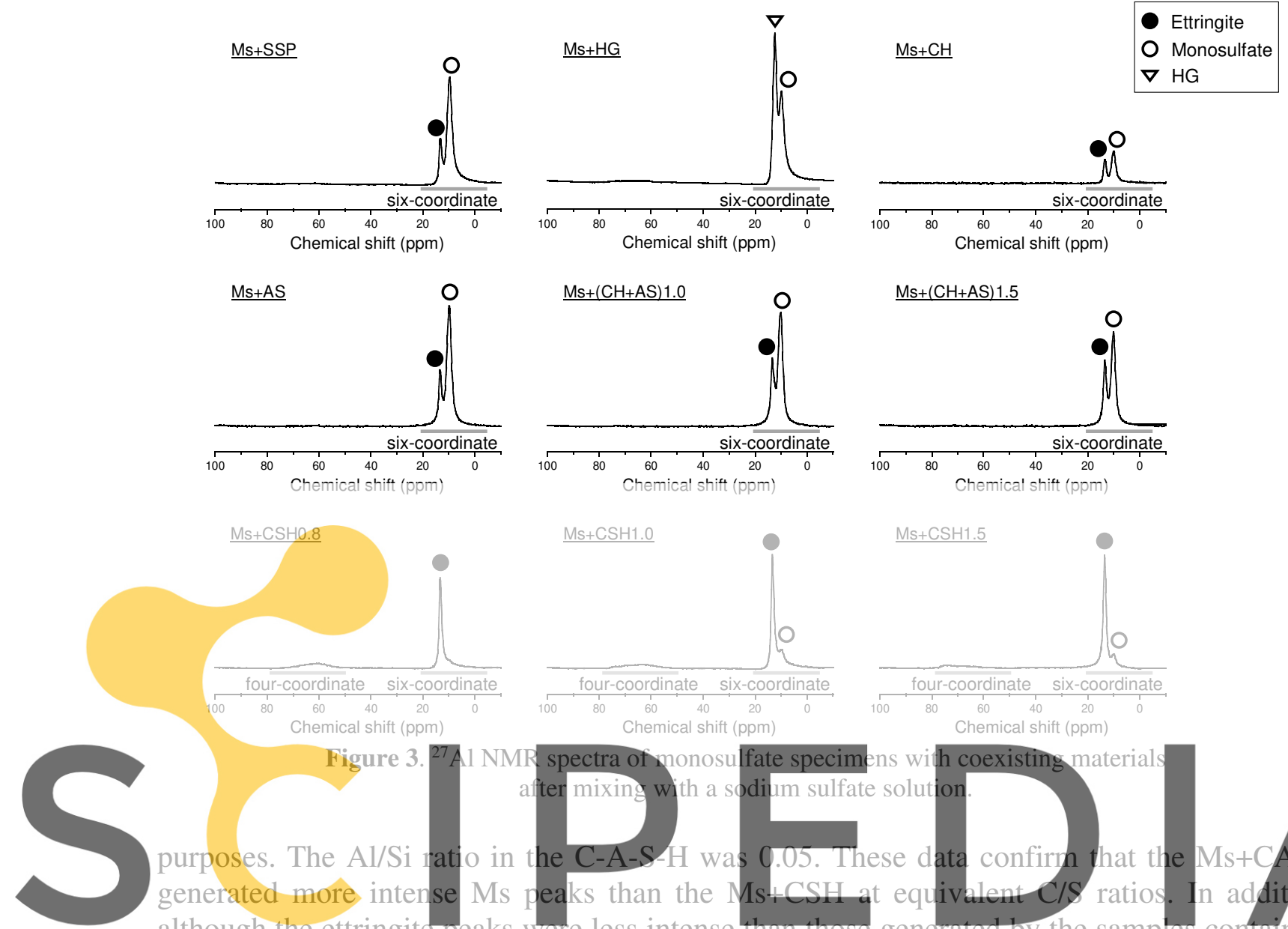

Figure 3,
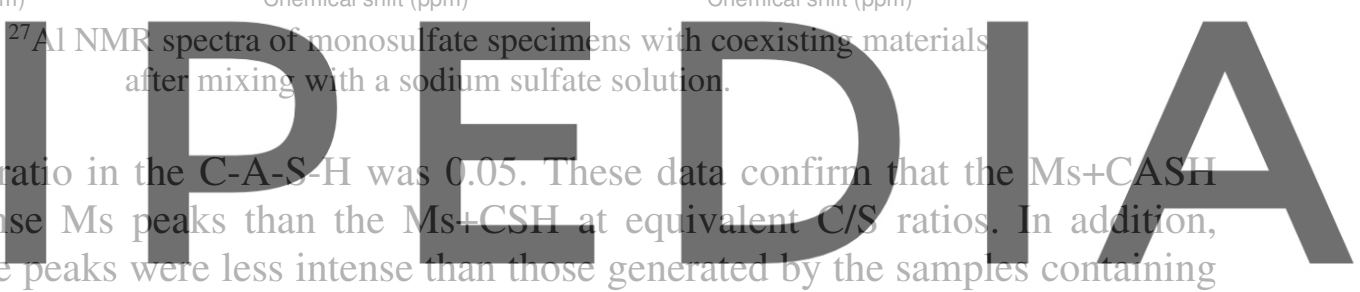

$\mathrm{C}-\mathrm{S}-\mathrm{H}$, these peaks were more intense compared with those generated by samples with other

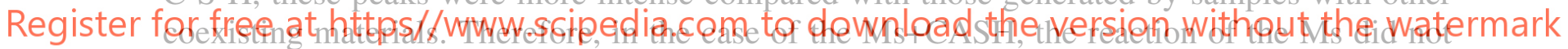

proceed as readily, although the ettringite peak was relatively high. These results suggest that

C-A-S-H contributed to the formation of secondary ettringite by supplying Ai.

Figure 5 provides the ${ }^{27} \mathrm{Al}$ NMR spectra of Ms samples with C-A-S-H after mixing with the sodium sulfate solution. These spectra confirm that the peak ascribed to six-coordinate $\mathrm{Al}$ in the Ms was more intense than those generated by specimens made with $\mathrm{C}-\mathrm{S}-\mathrm{H}$. The samples with C-A-S-H as the coexisting material also produced six-coordinate Al peaks corresponding to ettringite that were comparable to those obtained from the C-S-H samples.

The combined XRD and NMR data suggest that the presence of C-A-S-H promoted secondary ettringite formation primarily by consuming four-coordinate $\mathrm{Al}$ in the $\mathrm{C}-\mathrm{A}-\mathrm{S}-\mathrm{H}$.

\section{Discussion}

This work demonstrates that only the presence of C-S-H markedly increased the amount of secondary ettringite in the samples. The ${ }^{27} \mathrm{Al}$ NMR spectra show that four-coordinate $\mathrm{Al}$ appeared only in samples in which $\mathrm{C}-\mathrm{S}-\mathrm{H}$ coexisted with the $\mathrm{Ms}$, and this $\mathrm{Al}$ is attributed to the C-A-S-H (Richardson, 2004). Samples containing C-A-S-H were mixed with the sodium sulfate solution and examined by XRD and ${ }^{27} \mathrm{Al}$ NMR. The level of ettringite was found to be 

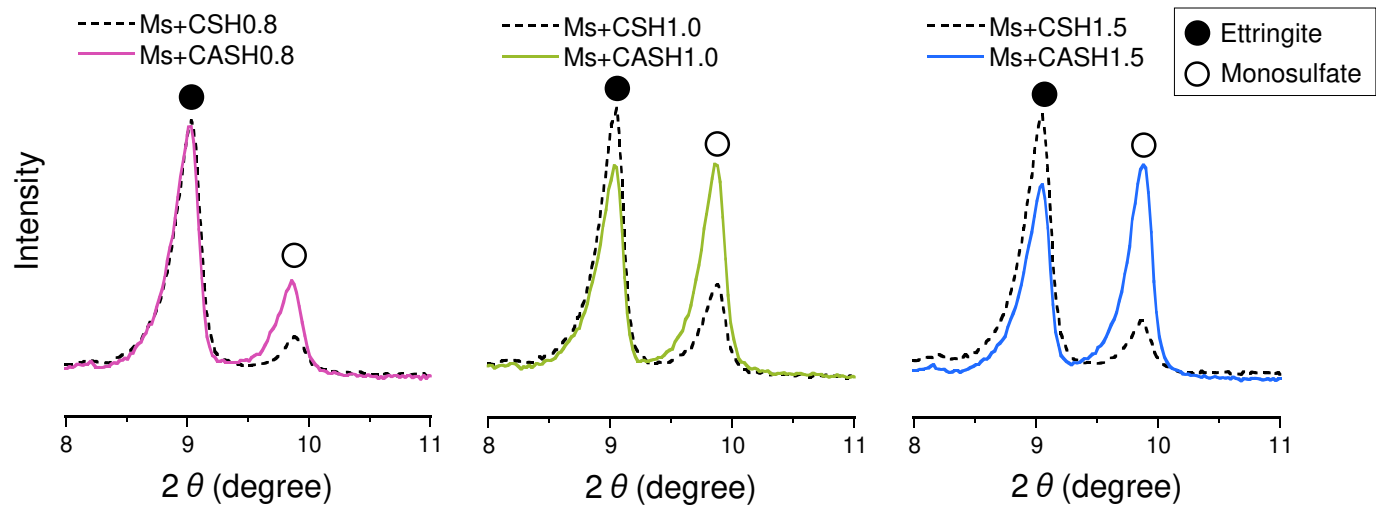

Figure 4. XRD patterns of monosulfate specimens with C-S-H or C-A-S-H after mixing with a sodium sulfate solution.
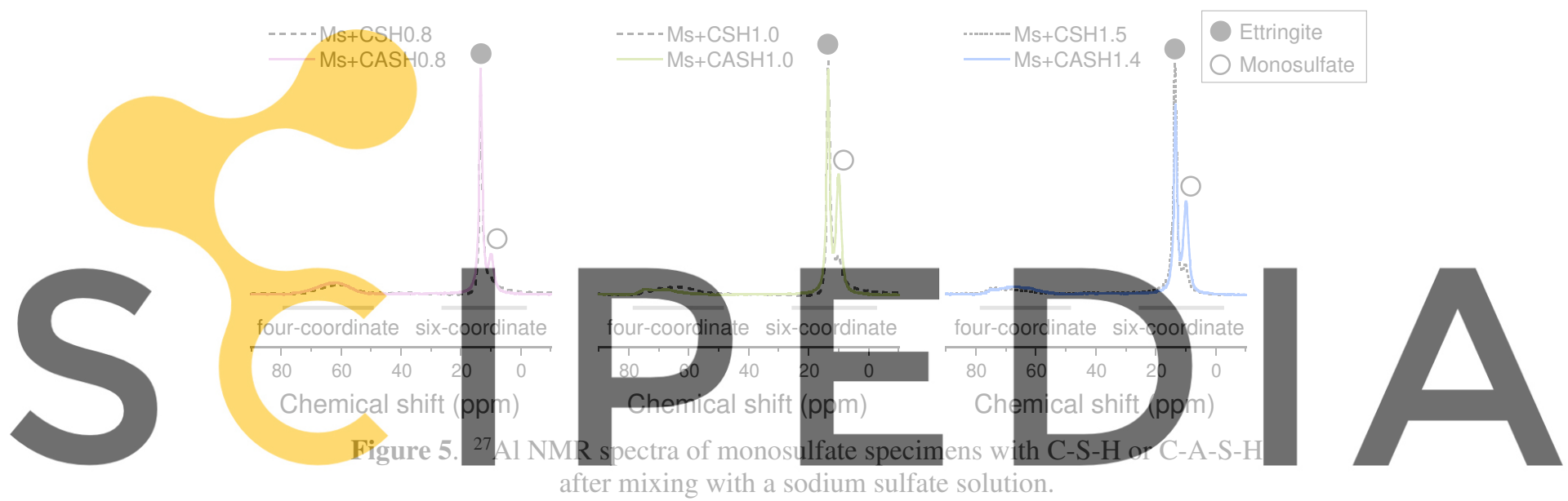

Register for free at https//www.scipedia.som to download the version without the watermark

These results suggest that the presence of four-coordinate Al is closely related to se condary ettringite formation, hence we assessed the Al coordination numbers in the samples. In the absence of coexisting materials, or when materials other than C-(A)-S-H coexist with the Ms (that is, when four-coordinate $\mathrm{Al}$ is not present), ettringite having six-coordinate $\mathrm{Al}$ is directly formed from Ms having the same six-coordinate Al. Under such conditions, the formation of secondary ettringite does not readily proceed.

In the case that $\mathrm{C}-\mathrm{S}-\mathrm{H}$ is present, $\mathrm{Al}$ released from the $\mathrm{Ms}$ is substituted into the silicate chains in the C-S-H. As a result, C-A-S-H is formed with four-coordinate Al. If a sufficient concentration of sulfate ions is available, ettringite is more likely to be formed from fourcoordinate $\mathrm{Al}$ than from the six-coordinate $\mathrm{Al}$ in the Ms. That is, the presence of $\mathrm{C}-\mathrm{S}-\mathrm{H}$ promotes secondary ettringite formation by changing the $\mathrm{Al}$ coordination number.

As such, ettringite is likely to be formed from four-coordinate $\mathrm{Al}$, and $\mathrm{C}-\mathrm{S}-\mathrm{H}$ promotes secondary ettringite formation by substituting $\mathrm{Al}$ into the silicate chains and converting sixcoordinate Al to four-coordinate. On the other hand, using SCMs is beneficial to decrease sulfate attack, while the production of C-A-S-H is increased with the amount of added SCMs. Based on the results of the present study, ettringite is likely to be formed when SCMs are used, 
however; the expansion is actually suppressed. Because of that, the expansion due to secondary ettringite formation may be related not only to the amount of ettringite but also to the location of ettringite formation.

\section{Conclusions}

The purpose of this study was to investigate experimentally the effects of coexisting materials on secondary ettringite formation. The conclusions can be summarized as follows.

- When monosulfate and C-S-H are mixed with a sodium sulfate solution, the amount of secondary ettringite is increased in comparison with other coexisting materials.

- $\quad$ The ${ }^{27} \mathrm{Al}$ NMR results confirm that C-A-S-H containing four-coordinate $\mathrm{Al}$ is formed in samples made with C-S-H. In addition, when C-A-S-H is added to the monosulfate, secondary ettringite is generated at a comparable level to that found in the C-S-H samples, although the monosulfate remains intact. It appears that ettringite is likely generated from four-coordinate $\mathrm{Al}$, and that $\mathrm{C}-\mathrm{S}-\mathrm{H}$ promotes secondary ettringite formation as a result of transitioning six-coordinate $\mathrm{Al}$ to four-coordinate $\mathrm{Al}$ by substituting $\mathrm{Al}$ in the Si chains.

\section{ORCID}

Kennosuke Sato: http://orcid.org/0000-0002-3456-4037

Tsuyoshi Saito: http://orcid.org/0000-0002-2335-5790

Tatsuhiko Saeki: http://orcie

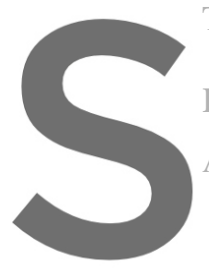

References

Andersen, M., D., Jakobsen, H., J. . and the C-S-H structure Cement and Concrete Retearch, 34

4, 857-868.
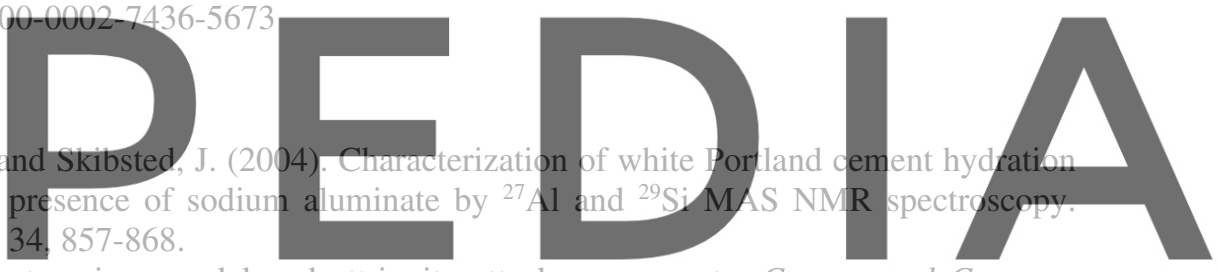
Composites, 25, 401-407.

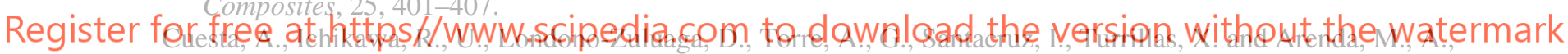
G. (2017). Aluminum hydroxide gel characterization within a calcium aluminate cement paste by combined Pair Distribution Function and Rietveld analysis. Cement and Concrete Research, 96, 1-12.

Kunther, W., Lothenbach, B. and Skibsted, J. (2015). Influence of the Ca/Si ratio of the C-S-H phase on the interaction with sulfate ions and its impact on the ettringite crystallization pressure. Cement and Concrete Research, 69, 37-49.

Pardal, X., Brunet, F., Charpentier, T., Pochard, I. and Nonat, A. (2012). ${ }^{27} \mathrm{Al}$ and ${ }^{29}$ Si Solid-State NMR Characterization of Calcium-Aluminosilicate-Hydrate. Inorganic Chemistry, 51, 1827-1836.

Pardal, X., Pochard, I. and Nonat, A. (2009). Experimantal study of Si-Al substitution in calcium-silicate-hydrate (C-S-H) prepared under equilibrium conditions. Cement and Concrete Research, 39, 637-643.

Renaudin, G., Russias, J., Leroux, F., Cau-dit-Coumers, C. and Frizon, F. (2009). Structural characterization of C-S-H and C-A-S-H samples - Part II: Local environment investigated by spectroscopic analysis. Journal of Solid State Chemistry, 182, 3320-3329.

Richardson, I., G. (2004). Tobermorite/jennite- and tobermorite/calcium hydroxide-based models for the structure of C-S-H: Applicability to hardened pastes of tricalcium silicate, $\beta$-dicalcium silicate, Portland cement, and blends of Portland cement with blast-furnace slag, metakaolin, or silica fume. Cement and Concrete Research, 34, 1733-1777.

Skibsted, J., Henderson, E. and Jakobsen, H., J. (1993). Characterization of calcium aluminate phases in cements by aluminum-27 MAS NMR spectroscopy. Inorganic Chemistry, 32, 1013-1027.

Taylor, H. F. W., Famy, C. and Scrivener, K. L. (2001). Delayed ettringite formation. Cement and Concrete Research, 31, 683-693. 